\title{
Enraizamento de estacas caulinares de Piper crassinervium Kunth sob diferentes concentrações de ácido indolbutírico
}

\author{
Erik Nunes Gomes ${ }^{1}$, Diones Krinski²
} ${ }^{1}$ Rutgers, The State University of New Jersey, School of Environmental and Biological Sciences, New Brunswick, New Jersey,
Estados Unidos. E-mail: e93gomes@gmail.com
${ }^{2}$ Universidade do Estado de Mato Grosso, Campus Universitário Professor Eugênio Carlos Stieler, Tangará da Serra, Mato Grosso,
Brasil. E-mail: diones.krinski@ unemat.br

Recebido: 24/07/2017; Aceito: 26/11/2018.

\section{RESUMO}

O objetivo do presente trabalho foi avaliar o efeito de diferentes concentrações do regulador vegetal ácido indolbutírico (AIB) no enraizamento e brotações de estacas caulinares de Piper crassinervium. Estacas caulinares de $12 \pm 1 \mathrm{~cm}$, contendo uma folha reduzida a um terço de seu tamanho, tiveram suas bases imersas por 15 segundos em soluções hidroalcoólicas (50\%) com concentrações de zero, 500, 1000, 2000 e $4000 \mathrm{mg} \mathrm{L}^{-1}$ de AIB. Após 45 dias da instalação do experimento, foram avaliadas as porcentagens de sobrevivência, enraizamento, estacas que mantiveram as folhas na região apical (retenção de folhas) e estacas com emissão de novas brotações, número, comprimento médio e massa seca de raízes e massa seca de brotações. Foram observadas altas porcentagens de enraizamento (média 75,83\%) e sobrevivência (média de 79,58\%), ambas não influenciadas pelas concentrações de AIB. As variáveis de porcentagens de estacas com novas brotações, massa seca de raiz e de brotações foram as únicas que apresentaram resposta significativa à aplicação do regulador, demonstrando inibição à medida que se aumentaram as concentrações. É viável a propagação de $P$. crassinervium via estaquia caulinar. A espécie apresenta altos índices de enraizamento e sobrevivência, não sendo necessária a aplicação do regulador vegetal AIB.

Palavras-chave: auxina, estaquia, jaguarandi, propagação vegetativa.

\section{Rooting of Piper crassinervium Kunth stem cuttings under different concentrations of indolebutyric acid}

\begin{abstract}
The objective of the present study was to evaluate the effect of different indolebutyric acid (IBA) concentrations on rooting and sprouting of Piper crassinervium stem cuttings. Cuttings of $12 \pm 1 \mathrm{~cm}$, containing one leaf reduced to one-third of its original size, had their bases immersed for 15 seconds in hydroalcoholic solutions (50\%) with concentrations of $0,500,1000,2000$ and $4000 \mathrm{mg} \mathrm{L}^{-1}$ of IBA. After 45 days from planting the cuttings, the percentages of survival, rooting, cuttings that maintained the leaves (retention of leaves) and sprouting, number, average length and dry mass of roots and dry mass of sprouts were evaluated. High rooting (average $75.83 \%$ ) and survival (average 79.58\%) were observed, both were not influenced by IBA concentrations. The sprouting percentage, roots and sprouts dry mass, were the only variables that showed a significant response to the application of the plant regulator, demonstrating inhibition as the IBA concentrations increased. The propagation of $P$. crassinervium via stem cuttings is viable. The species presents high rooting and survival rates, and the application of IBA is not necessary.
\end{abstract}

Keywords: auxin, cuttings, jaguarandi, vegetative propagation. 
O gênero Piper inclui cerca de 1000 espécies de paleoervas, frequentemente encontradas no sub-bosque, e vegetação secundária das florestas tropicais das Américas e Ásia (Guerrini et al., 2009). Espécies do gênero são frequentemente cultivadas por suas sementes e folhas, que possuem o aroma picante que as torna importantes especiarias, como é o caso da pimenta-doreino (Piper nigrum L.), largamente utilizada na culinária em diversos países (Srinivasan, 2007; Mgbeahuruike et al., 2017).

Além da importância comercial de $P$. nigrum, várias outras espécies do gênero Piper são conhecidas e cultivadas também por suas propriedades aromáticas e medicinais. O metabolismo secundário do gênero Piper é diverso e inclui alcaloides, terpenos e flavonoides (Perigo et al., 2016). Diversas espécies são utilizadas para o tratamento de várias doenças, tais como febre, cefaleia, diarreia, reumatismo, furúnculos, sarna e problemas de estômago (Mgbeahuruike et al., 2017).

Piper crassinervium Kunth, popularmente conhecida como jaguarandi, é uma espécie arbustiva, de 2 a 5 metros de altura, reconhecida principalmente pelas folhas de base simétrica, pelas nervuras secundárias conspícuas que partem em ângulo agudo na metade inferior da nervura mediana, pela espiga apiculada e pelo ovário, com estilete (Bardelli et al., 2008). A planta é bastante abundante na Mata Atlântica do Brasil, também ocorrendo naturalmente na Colômbia, Equador e Peru (Danelutte et al., 2003).

Segundo Albiero et al. (2005), dentre as espécies do gênero, $P$. crassinervium se destaca pelo emprego em fins terapêuticos. A espécie produz em seus frutos e folhas substâncias de rara ocorrência em organismos terrestres, as chamadas hidroquinonas preniladas, compostos caracterizados pelas suas propriedades antioxidantes e fungicidas (Danelutte et al., 2003; Yamaguchi et al., 2006). Além do potencial medicinal, são relativamente abundantes na literatura relatos da produção de óleo essencial nas folhas da espécie. São relatados rendimentos de 0,2 a $0,53 \%$, sendo os compostos majoritários mais comumente descritos: $\alpha$ pineno, $\beta$-pineno, trans-nerolidol, óxido de cariofileno, trans-cariofileno, $\beta$-cariofileno, $\gamma$-elemeno, $\beta$-elemeno, $\beta$-pireno, $\alpha$-pireno, limoneno e $\alpha$-terpineno (Luz et al., 2003; Sacchetti et al., 2005; Tognolini et al., 2006; Perigo et al., 2016).

Considerando a ausência de relatos do cultivo da espécie, a obtenção de matéria prima para obtenção de compostos de interesse se dá basicamente por meio do extrativismo das populações naturais. $\mathrm{O}$ extrativismo de plantas para uso medicinal nos ecossistemas tropicais tem levado a reduções drásticas nas populações naturais, devido ao processo predatório de exploração. Dessa maneira, a domesticação e cultivo surgem como alternativas viáveis para obtenção de matéria prima de interesse farmacêutico e redução do extrativismo nas formações florestais (Reis et al., 2007). O desenvolvimento de métodos de propagação adequados é uma das etapas inicias no processo de domesticação.

A propagação clonal das plantas por meio da estaquia é largamente reconhecida como método economicamente viável para o estabelecimento de plantios clonais, podendo ser viável para propagar espécies nativas (Dias et al., 2011). Dentre os aspectos relevantes na propagação via estaquia está a aplicação de reguladores vegetais. As auxinas são uma classe de reguladores envolvidos em muitos aspectos do crescimento e desenvolvimento de plantas. Quando aplicada em órgãos isolados, a auxina, dependendo de sua concentração, pode aumentar a resposta rizogênica (Bischoff et al., 2017).

Neste sentido, o objetivo do presente trabalho foi avaliar o efeito de diferentes concentrações do regulador vegetal AIB no enraizamento e brotações de estacas caulinares de $P$. crassinervium, visando à produção de mudas para domesticação da espécie.

O material vegetativo (ramos com folhas) para o preparo das estacas foi coletado a partir de 15 indivíduos de uma população espontânea, em vegetação de subosque localizada no município de Adrianópolis, Paraná (243'ㅇ $48^{\circ} 58^{\prime} \mathrm{W}$ - altitude $150 \mathrm{~m}$ ). A coleta foi realizada em dezembro de 2015 , no final da tarde (entre 16 e 17 horas)

O material foi umedecido com auxílio de garrafas plásticas preenchidas com água corrente e acondicionado em sacos de polietileno para o transporte até casa de vegetação, onde foi mantido sob nebulização intermitente por aproximadamente 12 horas até o preparo das estacas e instalação do experimento. Antes da confecção das estacas, o material vegetal foi lavado em água corrente por um período de 5 minutos.

Estacas caulinares, com diâmetro médio de $0,5 \mathrm{~cm}$, foram confeccionadas com comprimento de $12 \pm 1 \mathrm{~cm}$. Procedeu-se ao corte em diagonal (bisel) na base e reto no ápice, mantendo-se uma folha com um terço de sua área original na região apical da estaca. Os propágulos tiveram suas bases imersas por 15 segundos em soluções hidroalcoólicas (50\%), com concentrações de zero, 500, 1000, 2000 e $4000 \mathrm{mg} \mathrm{L}^{-1}$ de ácido indolbutírico (AIB). Após este procedimento, foram estaqueados em tubetes de $53 \mathrm{~cm}^{3}$ preenchidos com substrato comercial Tropstrato $\mathrm{HT}^{\circledR}$. Os tubetes foram dispostos de forma aleatória em suportes plásticos com capacidade para 96 tubetes e mantidos em casa de vegetação, sob nebulização intermitente de 5 segundos a cada 30 minutos durante a condução do experimento.

O delineamento experimental foi inteiramente casualizado com cinco tratamentos (quatro concentrações do regulador vegetal e um tratamento controle), quatro repetições e doze estacas por parcela. 
Após 45 dias da instalação do experimento, foram avaliadas as porcentagens de sobrevivência, enraizamento, estacas que mantiveram as folhas na região apical (retenção de folhas), estacas com emissão de novas brotações, número, comprimento médio e massa seca de raízes e massa seca das novas brotações.

Os dados foram submetidos à análise de homogeneidade de variâncias pelo teste de Bartlett e, quando homogêneos, submetidos à análise de regressão polinomial, verificando o ajuste nas equações linear e quadrática. $\mathrm{O}$ modelo a ser escolhido para representação dos dados foi o que obteve significância estatística $(\mathrm{p} \leq 0,05)$. Utilizou-se o programa estatístico Assistat 7.7 (Silva e Azevedo, 2016).

As diferentes concentrações de AIB influenciaram a porcentagem de estacas com brotações, massa seca de brotações e massa seca de raízes. Para as demais características, não foi observado efeito dos tratamentos nas equações linear e quadrática (Tabela 1 ).

A espécie apresentou altas porcentagens de enraizamento e sobrevivência $(75,83$ e $79,59 \%$, respectivamente), bem como retenção de folhas superior a $60 \%$ (Tabela 1). A porcentagem média de enraizamento pode ser considerada alta, especialmente quando comparada a outras espécies do gênero. Para $P$. amalago, por exemplo, Nunes-Gomes e Krinski (2016) relataram valores máximos de $22,92 \%$, com índices de mortalidade de até $95,83 \%$. Em estacas caulinares de $P$. umbellatum, Mattana et al. (2009) relataram porcentagens de até $37,5 \%$. Variações no potencial rizogênico de espécies vegetais dentro do mesmo gênero são comuns, e influenciadas, além dos aspectos genéticos, pela época de coleta do material propagativo, idade das plantas matrizes e condições gerais do ambiente de enraizamento (Zuffellato-Ribas e Rodrigues, 2001).

As estacas para a realização do presente experimento foram coletadas no fim de dezembro, período caracterizado pelo intenso crescimento vegetativo.
Estacas coletadas nesta época, via de regra, apresentamse mais herbáceas e com maior capacidade de enraizamento (Pizzatto et al., 2011), o que pode justificar os altos percentuais observados. A coleta em outras épocas do ano poderia apresentar dificuldades, como balanço hormonal desfavorável, menor atividade metabólica e presença de barreiras anatômicas. Estudos complementares avaliando tais fatores se fazem necessários para uma melhor compreensão da dinâmica de enraizamento da espécie e podem fornecer subsídios para um melhor planejamento da produção de mudas ao longo do ano.

Um dos efeitos adversos da época de coleta das estacas deste trabalho é o fato da maior possibilidade de desidratação em função do aumento das temperaturas (Cunha et al., 2009). Possivelmente não se observou este comportamento em $P$. crassinervium em função do caule da espécie ser recoberto por cutícula espessa (Albiero et al., 2005), o que constitui uma defesa anatômica à desidratação (Taiz e Zeiger, 2013). Além disso, o sistema de irrigação por nebulização intermitente propiciou condições de umidade constante, reduzindo consideravelmente a perda de água por transpiração. $\mathrm{O}$ fornecimento de condições meteorológicas adequadas em conjunto com características intrínsecas da espécie, propiciaram os altos níveis de sobrevivência e enraizamento observados.

Outro aspecto relevante, que pode explicar as altas porcentagens de enraizamento e sobrevivência, é o elevado índice de estacas com retenção de folhas, uma vez que estes órgãos são responsáveis pela síntese de auxinas e co-fatores para o enraizamento, além de serem fontes de carboidratos, que podem ser metabolizados em prol da sobrevivência dos propágulos (Bona e Biasi, 2010). Em estacas caulinares de $P$. amalago, os baixos valores de enraizamento foram atribuídos, entre outros aspectos, à baixa retenção foliar (Nunes-Gomes e Krinski, 2016).

Tabela 1. Resumo da análise de variância para porcentagens de enraizamento (ENR), sobrevivência (SOB), brotações (BRT) e retenção de folhas (RET), número (NUR), comprimento (CMR) e massa seca de raízes (MSR) e massa seca de brotações (MSB) em estacas caulinares de Piper crassinervium Kunth, sob diferentes concentrações do regulador vegetal ácido indolbutírico (AIB).

\begin{tabular}{cccccccccc}
\hline \multirow{2}{*}{$\begin{array}{c}\text { Fontes de } \\
\text { variação }\end{array}$} & G.L. & ENR & SOB & BRT & RET & NUR & CMR & MSR & MSB \\
& & $\%$ & $\%$ & $\%$ & $\%$ & & $\mathrm{~cm}$ & $\mathrm{mg}$ & $\mathrm{mg}$ \\
\hline Trat. & 4 & 187,5 & 168,4 & 675,7 & 312,5 & 3,2 & 0,3 & 2555,9 & 4289,4 \\
A.L. & 1 & $340,2 \mathrm{~ns}$ & $62,5 \mathrm{~ns}$ & $1632,7 * *$ & $27,7 \mathrm{~ns}$ & $4,6 \mathrm{~ns}$ & $0,7 \mathrm{~ns}$ & $8464,8^{* *}$ & $12437,3^{* *}$ \\
A.Q. & 1 & $401,7 \mathrm{~ns}$ & $496,0 \mathrm{~ns}$ & $463,5 \mathrm{~ns}$ & $714,2 \mathrm{~ns}$ & $8,2 \mathrm{~ns}$ & $0,4 \mathrm{~ns}$ & $1692,7 \mathrm{~ns}$ & $3911,1 \mathrm{~ns}$ \\
Erro & 15 & 254,6 & 200,2 & 148,9 & 258,1 & 2,2 & 0,5 & 1770,1 & 987,5 \\
\hline CV $(\%)$ & & 21,04 & 17,78 & 24,54 & 26,59 & 13,22 & 16,57 & 16,46 & 28,90 \\
\hline M.G & & 75,83 & 79,58 & 49,72 & 60,41 & 11,10 & 4,66 & 145,20 & 108,73 \\
\hline
\end{tabular}

**significativo a 1\%; *significativo a 5\%; ns: não significativo. C.V.: coeficiente de variação. G.L.: graus de liberdade; Trat.: tratamentos. A.L: ajuste linear. A.Q.: ajuste quadrático. M.G.: média geral. 
As altas porcentagens de enraizamento, aliadas à falta de resposta de boa parte das variáveis diretamente relacionadas ao sistema radicial (porcentagem de enraizamento, número e comprimento de raízes), permitem inferir que estacas caulinares de $P$. crassinervium já possuem condições endógenas adequadas ao enraizamento, não necessitando da aplicação de reguladores vegetais. Em estacas de Hibiscus rosa-sinensis L., Pizzatto et al. (2011), de modo semelhante ao presente trabalho, relataram porcentagens de enraizamento acima dos $70 \%$ sem aplicação de AIB, destacando que a espécie produz quantidades suficientes de auxinas endógenas, podendo ser classificada como de fácil propagação vegetativa. Neste sentido, considerando os valores observados no presente estudo, pode-se afirmar que $P$. crassinervium é uma espécie classificada como de fácil enraizamento.

Além da ineficiência do regulador vegetal na indução da rizogênese adventícia de $P$. crassinervium, foi observado na variável massa seca de raízes um efeito inibitório, com uma resposta linear negativa $(p<0,01)$ às concentrações do regulador vegetal, maiores valores (média de 186,66 mg) no tratamento controle e marcante decréscimo nas doses de 2000 e $4000 \mathrm{mg} \mathrm{L}^{-1}$ (Figura 1).

Fato semelhante foi observado em estacas de amoreira-preta, onde o aumento das concentrações de AIB foi prejudicial ao enraizamento. Segundo os autores, a aplicação provocou um desequilíbrio nos níveis endógenos de hormônios vegetais nas estacas, sobretudo auxinas, que poderiam já estar em níveis satisfatórios para o crescimento da planta (Dias et al., 2011).

Além da inibição da massa seca de raízes, as variáveis de porcentagem de estacas com novas brotações e massa seca de brotações também demonstraram tendência linear negativa às concentrações de AIB $(\mathrm{p}<0,01)$, todavia apresentando leve incremento na concentração de $500 \mathrm{mg} \mathrm{L}^{-1} \mathrm{em}$ relação ao tratamento controle e redução acentuada, especialmente na concentração de $4000 \mathrm{mg} \mathrm{L}^{-1}$ (Figuras 2 e 3$)$.

Em espécies do gênero Piper ( $P$. arboreum, $P$. amplum $e$ P. sp.), comportamento semelhante foi observado. Segundo os autores, a auxina sintética mobilizou nutrientes, inibindo a brotação quando aplicada na base da estaca (Magevski et al., 2011). No enraizamento do porta-enxerto de videira '43-43', também foram verificadas reduções nas brotações à medida que se aumentaram as concentrações do regulador vegetal (Botelho et al., 2005).

Em estacas de Rubus fruticosus, o uso de AIB causou decréscimo nas porcentagens de enraizamento e brotações, bem como diminuição no número médio de raízes e brotos e comprimento de brotos. Os autores sugerem que o regulador causou fitotoxidez às estacas, e que o teor endógeno de substâncias promotoras do enraizamento seria capaz de induzir este processo sem o uso de substâncias sintéticas (Tadeu et al., 2012), semelhantemente ao observado para $P$. crassinervium.

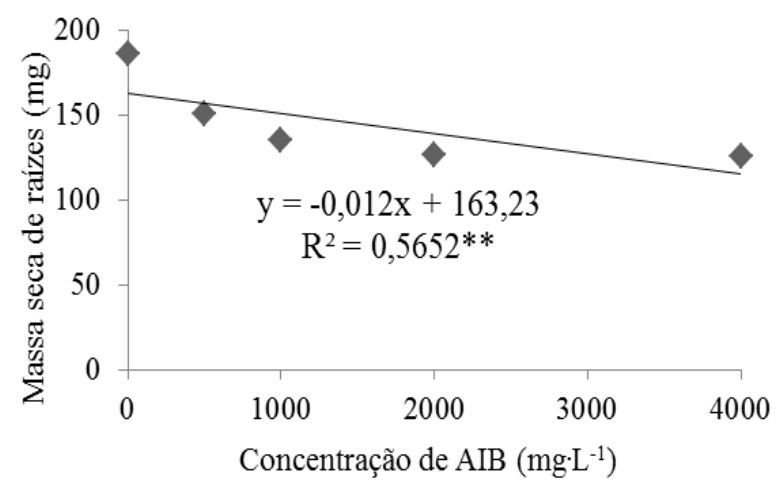

Figura 1. Massa seca de raízes em estacas de Piper crassinervium Kunth submetidas a diferentes concentrações de ácido indolbutírico.

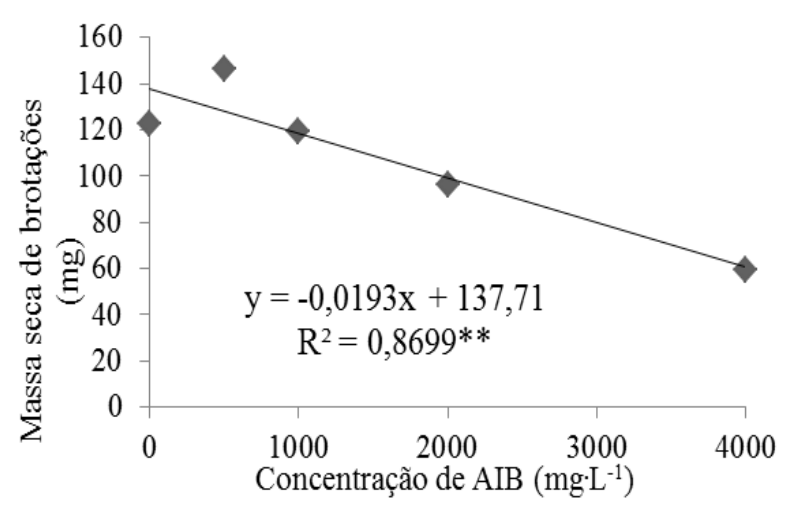

Figura 2. Massa seca de brotações em estacas de Piper crassinervium Kunth submetidas a diferentes concentrações de ácido indolbutírico.

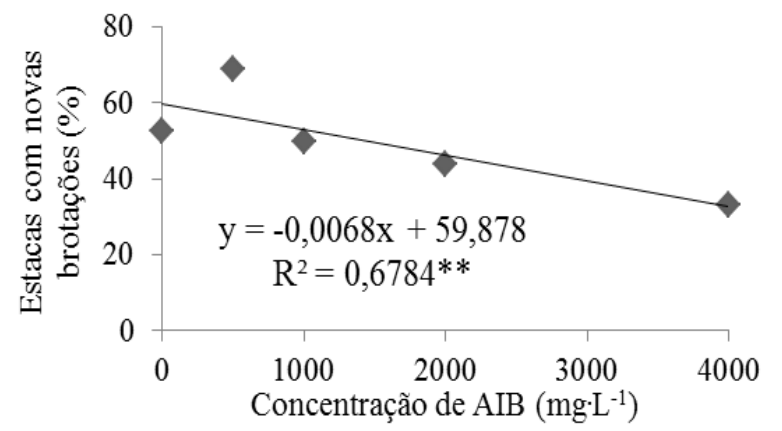

Figura 3. Porcentagem de estacas de Piper crassinervium Kunth com emissão de novas brotações em função de diferentes concentrações de ácido indolbutírico.

Destaca-se que o presente estudo é um dos primeiros publicados com o objetivo de definir práticas agronômicas para a exploração da espécie. Além da possibilidade de exploração econômica, técnicas adequadas de propagação fornecem alternativas para conservação por meio do cultivo, não restringindo a exploração ao extrativismo. 
É viável a propagação de $P$. crassinervium por estaquia caulinar. A espécie apresenta altos índices de enraizamento e sobrevivência, não sendo necessária a aplicação do regulador vegetal ácido indolbutírico. Recomendam-se estudos complementares avaliando, especialmente a sazonalidade, visando à disponibilidade de mudas em diversas épocas do ano, bem como ensaios avaliando a adaptação das mudas a diferentes ambientes de cultivo.

\section{Agradecimentos}

Os autores agradecem ao biólogo Bruno Felipe Camera, pelo auxílio na coleta e confecção das estacas, à Universidade Federal do Paraná, pela disponibilização de substratos e estrutura para a instalação dos experimentos, e à CAPES, pela concessão de bolsas aos autores na ocasião da condução do experimento.

\section{Referências Bibliográficas}

Albiero, A.L.M., Paoli, A.A.S., Souza, L.A.D., Mourão, K.S. M., 2005. Morphology and anatomy of vegetative organs of Piper crassinervium HB \& K. (Piperaceae). Acta Botanica Brasilica, 19, 305-312.

Bardelli, K.C., Kirizawa, M., Sousa, A.V.G.D., 2008. O gênero Piper L. (Piperaceae) da Mata Atlântica da Microbacia do Sítio Cabuçu-Proguaru, Guarulhos, SP, Brasil. Hoehnea, 35, 553-561.

Bischoff, A., Vendramim, D., Nunes Gomes, E., ZuffellatoRibas, K., Engel, M., Maggioni, R., 2017. Enraizamento de estacas de erva-baleeira em função de diferentes concentrações de ácido indol butírico e número de folhas. Revista de Ciências Agroveterinárias, 16, 41-47.

Bona, C.M., Biasi, L.A., 2010. Influence of leaf retention on cutting propagation of Lavandula dentata L. Revista Ceres, $57,526-529$.

Botelho, R.V., Maia, A.J., Pires, E.J.P., Terra, M.M., Schuck, E., 2005. Efeitos de reguladores vegetais na propagação vegetativa do porta-enxerto de videira '43-43' (Vitis vinifera $\mathrm{x}$ V. rotundifolia). Revista Brasileira de Fruticultura, 27, 6-8.

Cunha, A.C.M.D., Paiva, H.N.D., Leite, H.G., Barros, N.F. D., Leite, F.P., 2009. Relações entre variáveis climáticas com produção e enraizamento de miniestacas de eucalipto. Revista Árvore, 33, 195-203.

Danelutte, A.P., Lago, J.H.G., Young, M.C.M., Kato, M.J., 2003. Antifungal flavanones and prenylated hydroquinones from Piper crassinervium Kunth. Phytochemistry, 64, 555559.

Dias, J.P.T., Ono, E.O., Rodrigues, J.D., 2011. IBA e carboidratos no enraizamento de brotações procedentes de estacas radiciais de Rubus spp. Revista Brasileira de Fruticultura, 33, 666-671.
Guerrini, A., Sacchetti, G., Rossi, D., Paganetto, G., Muzzoli, M., Andreotti, E., Bruni, R., 2009. Bioactivities of Piper aduncum L. and Piper obliquum Ruiz \& Pavon (Piperaceae) essential oils from eastern Ecuador. Environmental toxicology and pharmacology, 27, 39-48.

Luz, A.I.R., Zoghbi, M.D.G.B., Maia, J.G.S., 2003. The essential oils of Piper reticulatum L. and P. crassinervium HB K. Acta Amazonica, 33, 341-344.

Magevski, G.C., Czepak, M.P., Schmildt, E.R., Alexandre, R.S., Fernandes, A.A., 2011. Propagação vegetativa de espécies silvestres do gênero Piper, com potencial para uso como porta enxertos em pimenta-do-reino (Piper nigrun). Revista Brasileira de Plantas Medicinais, 13, n. spe, 559-563.

Mattana, R.S., Franco, V.F., Yamaki, H.O., Almeida, M.E., Ming, L.C., 2009. Propagação vegetativa de plantas de pariparoba [Pothomorphe umbellata (L.) Miq.] em diferentes substratos e número de nós das estacas. Revista Brasileira de Plantas Medicinais, 11, 325-329.

Mgbeahuruike, E.E., Yrjönen, T., Vuorela, H., Holm, Y., 2017. Bioactive compounds from medicinal plants: Focus on Piper species. South African Journal of Botany, 112, 54-69.

Nunes Gomes, E., Krinski, D., 2016. Propagação vegetativa de Piper amalago (Piperaceae) em função de tipos de estaca e substratos. Cultura Agronômica, 25, 199-210.

Perigo, C.V., Torres, R.B., Bernacci, L.C., Guimarães, E.F., Haber, L.L., Facanali, R., Marques, M.O.M., 02016. The chemical composition and antibacterial activity of eleven Piper species from distinct rainforest areas in Southeastern Brazil. Industrial Crops and Products, 94, 528-539.

Pizzatto, M., Wagner-Júnior, A., Luckmann, D., Pirola, K., Cassol, D.A., Mazaro, S.M., 2011. Influência do uso de AIB, época de coleta e tamanho de estaca na propagação vegetativa de hibisco por estaquia. Revista Ceres, 58, 487-492.

Reis, M.S., Mariot, A., Steenbock, W., 2007. Diversidade e domesticação de plantas medicinais, in: Simões, C. M. O., Schenkel, E.P., Gosmann, G., Mello, J.C.P, Mentz, L.A., Petrovick, P.R. (Eds.), Farmacognosia da planta ao medicamento. 6. ed. UFRGS/EDUFSC., Porto Alegre-RS, pp.45-69.

Sacchetti, G., Maietti, S., Muzzoli, M., Scaglianti, M., Manfredini, S., Radice, M., Bruni, R., 2005. Comparative evaluation of 11 essential oils of different origin as functional antioxidants, antiradicals and antimicrobials in foods. Food chemistry, 91, 621-632.

Silva, F.A.S., Azevedo, C.A.V., 2016. Comparison of means of agricultural experimentation data through different tests using the software Assistat. African Journal of Agricultural Research, 11, 3527-3531.

Srinivasan, K., 2007. Black Pepper and its pungent principlepiperine: A review of diverse physiological effects. Critical Reviews in Food Science and Nutrition, 47, 735-748.

Tadeu, H.M., Pio, R., Tiberti, S.A., Figueiredo, M., Souza, F. B.M., 2012. Enraizamento de estacas caulinares e radiculares de Rubus fruticosus tratadas com AIB. Revista Ceres, 59, 881884 . 
Taiz, L., Zeiger, E., 2013. Fisiologia vegetal, fifth ed. Artmed, Porto Alegre-RS.

Tognolini, M, Barocelli, E., Ballabeni, V., Bruni, R., Bianchi, A., Chiavarini, M, Impicciatore, M., 2006. Comparative screening of plant essential oils: phenylpropanoid moiety as basic core for antiplatelet activity. Life sciences, 78, 14191432.
Yamaguchi, L.F., Lago, J.H.G., Tanizaki, T.M., Mascio, P.D. Kato, M.J., 2006. Antioxidant activity of prenylated hydroquinone and benzoic acid derivatives from Piper crassinervium Kunth. Phytochemistry, 67, 1838-1843.

Zuffellato-Ribas, K.C., Rodrigues, J.D., 2001. Estaquia: uma abordagem dos principais aspectos fisiologicos. UFPR, Curitiba-PR 